\title{
Teaching of Chemistry Applied. Development of a Laboratory-scale Fire Started
}

\author{
Vanina A. Guntero ${ }^{1,2}$, Pedro M.E. Mancini ${ }^{1}$, Cristián A. Ferretti ${ }^{1,3}$, María N. Kneeteman ${ }^{1, *}$ \\ ${ }^{1}$ IQAL (UNL-CONICET), Laboratorio Fester - QUÍMICA ORGÁNICA, Universidad Nacional del Litoral, Facultad de Ingeniería \\ Química, 3000, Santa Fe, Argentina \\ ${ }^{2}$ Universidad Tecnológica Nacional - Facultad Regional San Francisco, San Francisco, 2400, Argentina \\ ${ }^{3}$ INCAPE (UNL-CONICET), 3000, Santa Fe, Argentina \\ *Corresponding author: mkneeteman@fiq.unl.edu.ar
}

\begin{abstract}
The present laboratory work based in the preparation of fire started is proposed as an alternative in the teaching of chemistry for students of high school, with the purpose of articulate and integrate the abilities of students from the knowledge acquired. In this sense, is proposed the progression of learning, so that students develop from a specific concept towards the understanding of a phenomenon through a concrete and accessible teaching practice that assure that interaction. This practice allowed consolidating and expanding the teaching-learning process. Based on the interest in the topic propounded, the students were able to internalize the knowledge, reaching a satisfactory theoretical-practical relationship.
\end{abstract}

Keywords: chemistry, fire starter, teaching in context, laboratory work

Cite This Article: Vanina A. Guntero, Pedro M.E. Mancini, Cristián A. Ferretti, and María N. Kneeteman, "Teaching of Chemistry Applied. Development of a Laboratory-scale Fire Started." World Journal of Chemical Education, vol. 6, no. 2 (2018): 87-90. doi: 10.12691/wjce-6-2-2.

\section{Introduction}

There are a lot of investigations that highlight the implementation of laboratory work $[1,2,3,4,5,6]$. This arise like result to reach a better understanding of phenomenon promoting changes in students' ideas and making it possible to relate the issues studied to what happens at the social level $[7,8]$. This was combined with the necessity to learn the technical approach present in the determination of observations and theories part of process [9]. The experimental activities in the teaching of chemistry represent an important component in the curricular development $[9,10]$. These activities are defined such part of learning through interaction with materials and/or models to observe and understand the natural work $[11,12]$. These practices usually wake up the interest of actors, and in this way achieve a greater degree of activity in the learning process, achieving a conceptual understanding and a more flexible use of knowledge $[8,12]$. As a way to continue the proposals for experimental chemistry teaching it was proposed the realization of a practical work referred to the development of a fire starter. Fire starter is used in domestic application or as a camping article.

The main objective of this experimental work was to introduce the students of high school in the preparation of fire starters as a way of learning chemistry. For this, it was necessary show the relation between concepts and applications, promote the adoption of knowledge from a laboratory, stimulate collaborative group, use the previous knowledge, and generate possible micro entrepreneurs. Besides, it is allowed apply contents already acquired, for example, the molecular structure and functional groups of the precursors, solubility, density, viscosity, complete and incomplete combustion reaction, ignition temperature, and a series of dyes.

Students are expected to connect and correlate theory and practice. The intervention of the teacher is related with the monitoring of the advances, intervention and stimulation the students in the redaction to reports and develop a cooperative work in the communication of results.

\section{Methodology}

The methodological sequence was divided in five stages (Figure 1). The first was developed by the teacher through explanation, introducing students in the study of chemistry. The main concepts developed were: safety standards in laboratories, chemical families of compounds and their physics properties. In the second stage, the class (15 students) was divided into teams of 3 students each. They must look information related to fire starter. They looked for information of reagents data sheets, identification of functional groups, physics properties, safety standards for handling reagents and equipment, and functions of reagents in the fire starter. The third stage consisted of obtaining natural dyes through the technique of maceration from different matrices. During the fourth stage the fire starters were developed in the laboratory. In the last stage, the students had to write the reports and communicate the results. 


\section{Results and Discussion}

Based on the bibliographic search and analysis [13], all the groups selected as base reagents carbopol (cross-linked polyacrylate polymer), triethanolamine (TEA), distilled water and ethanol. Amine was selected for its excellent properties of gelification, ethanol was chosen like combustible and a carbopol by its properties as thickener (Table 1).

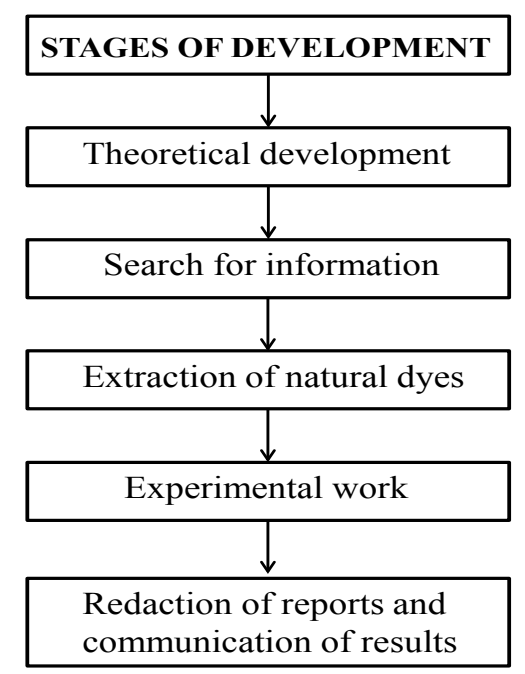

Figure 1. Methodological sequence of the stages developed

Table 1. Chemical compounds and their physical properties studied by students

\begin{tabular}{|l|l|}
\hline Chemical compound & Physical properties \\
\hline \multirow{5}{*}{ Carbopol } & White powder \\
& Solubility: water, ethanol, glycerin \\
& Hygroscopic \\
& Emulsifying, viscosifying and gelling agent \\
\hline & Liquid \\
& Colorless \\
& Solubility: water, ethanol \\
& Viscous \\
& Hygroscopic \\
& Gelling agent \\
& BP: $335^{\circ} \mathrm{C}$ \\
& MW: $149.188 \mathrm{~g} / \mathrm{mol}$ \\
\hline \multirow{5}{*}{ TEA } & Liquid \\
& Colorless \\
& Characteristic smell \\
& Solubility: water \\
& BP: $79^{\circ} \mathrm{C}$ \\
& MW: $46.1 \mathrm{~g} / \mathrm{mol}$ \\
\hline \multirow{5}{*}{ Stearic acid } & Crystal solid \\
& Colorless \\
& Odourless \\
& MW: $381.4 \mathrm{~g} / \mathrm{mol}$ \\
& MP: $75^{\circ} \mathrm{C}$ \\
\hline & White powder \\
& Solubility: ethanol \\
& MW: $284.48 \mathrm{~g} / \mathrm{mol}$ \\
& MP: $70^{\circ} \mathrm{C}$ \\
\hline
\end{tabular}

Table 2 shows the basic conditions of safety and hygiene in laboratory work and the handling of reagents.

Table 2. Basic conditions of safety and hygiene in laboratory work and the handling of reagents

Personal protection: smock, latex gloves, mask, glasses

Hygiene's norm

Reading the instructions on the label before using the reagents

Label the vessel properly
On the other hand, students developed a table with reagents and their respective molecular formula and semideveloped structural formula as show in Table 3 .

Table 3. Molecular and semi-developed formulas of chemical compounds

\begin{tabular}{|c|c|c|}
\hline $\begin{array}{c}\text { Chemical } \\
\text { compound }\end{array}$ & $\begin{array}{c}\text { Molecular } \\
\text { formula }\end{array}$ & $\begin{array}{c}\text { Semi-developed structural } \\
\text { formula }\end{array}$ \\
\hline Carbopol & $\left(\mathrm{C}_{3} \mathrm{H}_{4} \mathrm{O}_{2}\right) \mathrm{n}$ & $-\left[\mathrm{CH}_{2} \mathrm{CH}(\mathrm{COOH})\right] \mathrm{n}$ \\
\hline TEA & $\mathrm{C}_{6} \mathrm{H}_{15} \mathrm{NO}_{3}$ & $\begin{array}{c}\mathrm{HOH}_{2} \mathrm{CH}_{2} \mathrm{C}-\mathrm{N}_{-} \mathrm{CH}_{2} \mathrm{CH}_{2} \mathrm{OH} \\
\mathrm{CH}_{2} \mathrm{CH}_{2} \mathrm{OH}\end{array}$ \\
\hline Ethanol & $\mathrm{C}_{2} \mathrm{H}_{6} \mathrm{O}$ & $\mathrm{CH}_{3} \mathrm{CH}_{2} \mathrm{OH}$ \\
\hline Borax & $\mathrm{Na}_{2} \mathrm{~B}_{4} \mathrm{O}_{7} \cdot 10 \mathrm{H}_{2} \mathrm{O}$ & $2 \mathrm{Na}^{+1}\left[\mathrm{~B}_{4} \mathrm{O}_{5}(\mathrm{OH})_{4}\right]^{2-}$ \\
\hline Stearic acid & $\mathrm{C}_{18} \mathrm{H}_{36} \mathrm{O}_{2}$ & $\mathrm{CH}_{3}\left(\mathrm{CH}_{2}\right)_{16} \mathrm{COOH}$ \\
\hline
\end{tabular}

The next step was the search of natural dyes and/or allow to food, because the main use of the initiators will be for cooking foods. Some of the properties that should be considered in the election were solubility and lack of reactivity in contact with light or atmospheric oxygen.

Group I used dye extracted of beet with ethanol. Group II used dye extracted of chard with ethanol. Additionally, group II proposed an alternative that consisted in making solid initiators. They used borax (disodium tetraborate decahydrate), stearic acid and ethanol. Borax has an amphoteric behavior, if loses its hydration it becomes in tincalconite. Group III used dye extracted of cabbage with ethanol. Groups IV and V chose dye allow to Argentine Food Code (C.A.A.) [14]. Table 4 shows reagents, dye and quantities used. The dye was added at the end.

Table 4. Composition of fire starter proposal by groups

\begin{tabular}{|c|ccc|}
\hline \multicolumn{3}{|c}{ Composition } \\
\hline \multirow{4}{*}{ Group I } & Carbopol & Distilled water & Triethanolamine \\
\cline { 2 - 4 } & $0.364 \mathrm{~g}$ & $25 \mathrm{ml}$ & 8 drops \\
\hline \multirow{4}{*}{ Group II } & Dye & Stirring & Ethanol \\
& Carbopol & Distilled water & Triethanolamine \\
& $0.3008 \mathrm{~g}$ & $25 \mathrm{ml}$ & 8 drops \\
\cline { 2 - 4 } & Dye & Stirring & Ethanol \\
& $10 \mathrm{ml}$ & $30 \mathrm{~min}$ & $10 \mathrm{ml}$ \\
\hline \multirow{4}{*}{ Group III } & Carbopol & Distilled water & Triethanolamine \\
& $0.3003 \mathrm{~g}$ & $25 \mathrm{ml}$ & 8 drops \\
\cline { 2 - 4 } & Dye & Stirring & Sodium bicarbonate \\
& $30 \mathrm{ml}$ & $50 \mathrm{~min}$ & $0.1102 \mathrm{~g}$ \\
\hline \multirow{4}{*}{ Group IV } & Carbopol & Distilled water & Triethanolamine \\
& $0.3150 \mathrm{~g}$ & $25 \mathrm{ml}$ & 6 drops \\
\cline { 2 - 4 } & Dye & Stirring & Ethanol \\
& $1 \mathrm{ml}$ & $30 \mathrm{~min}$ & $10 \mathrm{ml}$ \\
\hline \multirow{5}{*}{ Group V } & Carbopol & Distilled water & Triethanolamine \\
& $0.3252 \mathrm{~g}$ & $25 \mathrm{ml}$ & 8 drops \\
\cline { 2 - 4 } & Dye & Stirring & Ethanol \\
& $0.01 \mathrm{~g}$ & $30 \mathrm{~min}$ & $10 \mathrm{ml}$ \\
\hline & & &
\end{tabular}

Table 5 shows composition of solid fire initiator. Both, borax and stearic acid were added to ethanol previously heating until dissolution. Then, were mixed, dye was added, and it was allowed cool to room temperature.

The final stage consisted of the group delivery of the report and the socialization. Each group realized the exposition for 20 minutes. 
Table 5. Composition of solid fire starter proposal by group II

\begin{tabular}{|c|ccc|}
\hline \multirow{2}{*}{ Experiment I } & \multicolumn{3}{c|}{ Composition } \\
\cline { 2 - 4 } & $0.364 \mathrm{~g}$ & $1.5683 \mathrm{~g}$ & $30 \mathrm{ml}$ \\
\hline \multirow{2}{*}{ Experiment II } & Borax & Stearic acid & Ethanol \\
\cline { 2 - 4 } & $1.0181 \mathrm{~g}$ & $2.0364 \mathrm{~g}$ & $30 \mathrm{ml}$ \\
\hline \multirow{2}{*}{ Experiment III } & Borax & Stearic acid & Ethanol \\
\cline { 2 - 4 } & $2.0605 \mathrm{~g}$ & $1.0258 \mathrm{~g}$ & $30 \mathrm{ml}$ \\
\hline \multirow{2}{*}{ Experiment IV } & Borax & Stearic acid & Ethanol \\
\cline { 2 - 4 } & $1.5172 \mathrm{~g}$ & $1.0384 \mathrm{~g}$ & $50 \mathrm{ml}$ \\
\hline \multirow{2}{*}{ Experiment V } & Borax & Stearic acid & Ethanol \\
\cline { 2 - 4 } & $1.0048 \mathrm{~g}$ & $1.5517 \mathrm{~g}$ & $50 \mathrm{ml}$ \\
\hline
\end{tabular}

The students delivered the report on time established. They were able to conclude that exist critical values, which define properties of gel.

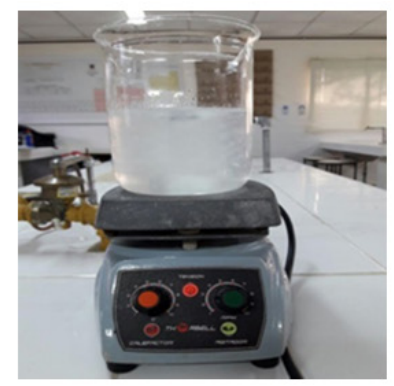

(a)

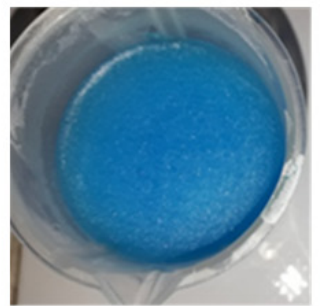

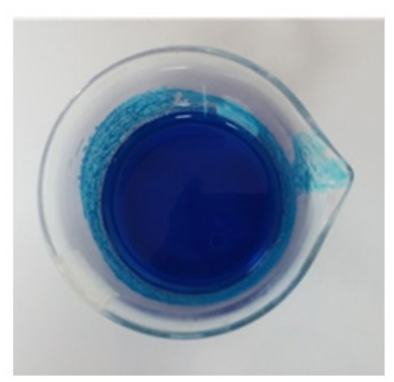

(b)

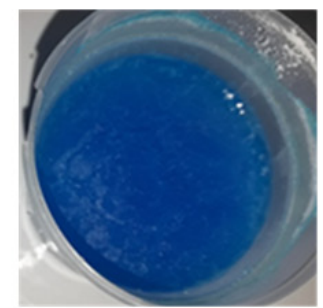

(c)

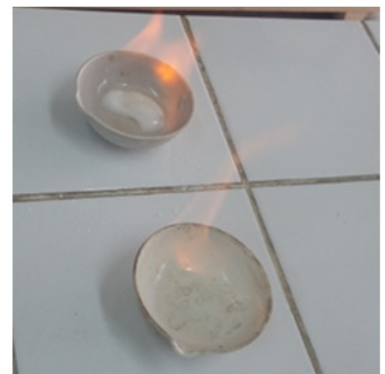

(d)

Figure 2. Fire starter (a) gel, without dye (b) gel, group IV (c) gel, group $\mathrm{V}$ (d) solid, group II, behind experiment 5

Groups I and II concluded that natural dye caused loss of color and changes of texture in the starter. Results show in Table 2 allowed to conclude that starter of experiment 5 produced most vigorous flame followed by experiments 3 and 4, whereas experiment 1 and 2 were rejected because did not light, probably by the most content of stearic acid.

Group III got a product with suitable consistency. Sodium bicarbonate added made possible that violet dye turned a dark blue, achieving the desired color. Besides sodium bicarbonate has a stabilizing function.

Groups IV and V obtained fire starter with desired consistency and color. They chose azoic type dye.

Reports were socialized. During exposition, students were able to base the decisions made based on the results obtained. Activities were realized for a week, $4 \mathrm{~h}$ daily. All groups had access to reagents and material of laboratory. Figure 2 show part of process realized.

\section{Conclusion}

This practical work based in the preparation of fire started allows reinforcing and enriching the teachinglearning process related to specific contents of chemistry.

The methodology proposed stimulates students in different aspects. Participants were involved in conceptual issues, which then were developed in a practical way. The formal discussion of the topic addressed offers a better understanding of the basic concepts, which allows guiding students in the rediscovery of scientific content.

During it was possible explore how influences a class innovation in the perceptions of students about science. The characteristics of this approach allowed achieving an integral development, improving the results and providing the basis for a future entrepreneurship.

The context helped students to question methodologies, to enhance their desire to learn, to develop their cognitive and experimental skills, and to infer what aspects need improvement.

The fire starters obtained totally exceeded the proposal.

During these practices, students were able to compile, analyze and interpret data, solve problem situations, propose answers and communicate the result.

\section{Acknowledgements}

Authors thank the Agencia Nacional de Ciencia y Tecnología (ANCyT) of Argentina, PICT 2014 No 1587, CAI+D 2016-2020 PE $\mathrm{N}^{\circ}$ 50420150100056LI of the Universidad Nacional del Litoral, Santa Fe, Argentina and Universidad Tecnológica Nacional for financial support of this work.

\section{References}

[1] E.M. Costel, "Didactic Options for the Environmental Education," Procedia - Soc. Behav. Sci., 180, 1380-1385, 2015.

[2] A. Ovaya V., Y.M. Vargas R., and G. Delgadillo G., “Aspectos relevantes de la educación basada en competencias para la formación profesional," Educ. Química, 22 (1), 63-68, 2011.

[3] D.A. Canelas, J.L. Hill, and A. Novicki, "Cooperative learning in organic chemistry increases student assessment of learning gains in key transferable skills," Chem. Educ. Res. Pract., 18, 441-456, 2017.

[4] M.A. Buntine, J.R. Read, S.C. Barrie, R.B. Bucat, G.T. Crisp, A.V. George, I.M. Jamie and S.H. Kable, "Advancing Chemistry by Enhancing Learning in the Laboratory (ACELL): a model for providing professional and personal development and facilitating improved student laboratory learning outcomes," 8 (2), 232-254, 2006. 
[5] A. Borgobello, N.S. Peralta, and N.D. Roselli, "Interaction among experience, teaching performance and student's learning at university level," Estudos de Psicologia, 30, 169-176, 2013.

[6] X. Pang, "Application of chlor-alkali \& polyvinyl chloride procedure in the teaching of 'chemical engineering basic' course," Int. Educ. Res. J., 2 (11), 17-18, 2016.

[7] M. Kalathaki, "A Design Tool of Didactic Scenarios for Science Teaching in Secondary Education," Int. J. Adv. Res. Educ. Technol., 3(3), 185-191, 2016.

[8] N. Akkuzu and M.A. Uyulgan, "An epistemological inquiry into organic chemistry education: exploration of undergraduate students' conceptual understanding of functional groups," Chem. Educ. Res. Pract., 17, 36-57, 2013.

[9] H.Y. Agustian and M.K. Seery, "Reasserting the role of prelaboratory activities in chemistry education: a proposed framework for their design," Chem. Educ. Res. Pr., 18(1), 518-532, 2017.
[10] V.A. Guntero, P.M. Mancini, and M.N. Kneeteman, "Introducing Organic Chemistry Students to the Extraction of Natural Products Found in Vegetal Species," World J. Chem. Educ., 5(4), 142-147, 2017.

[11] S.B. Boesdorfer and R.A. Livermore, "Secondary school chemistry teacher's current use of laboratory activities and the impact of expense on their laboratory choices," Chem. Educ. Res. Pr., 2017.

[12] Ö. Ciçek and N. İlhan, "Evaluating Interest in Acids-bases: Development of an Acid-Base Interest Scale (ABIS) and Assessment of Pre-service Science Teachers' Interest," Chem. Educ. Res. Pract., 00, 1-3, 2013.

[13] V.A. Guntero, M.N. Kneeteman, and P.M. Mancini, "Preparation of Gel Alcohol Flavored with Essential Oils. An Employ of Laboratory Techniques in the Organic Chemistry Study," World J. Chem. Educ., 5(3), 86-90, 2017.

[14] [Online]. Available: http://www.anmat.gov.ar, "Código Alimentario Argentino." 